\title{
Naturwissenschaften: recent advances, changes and challenges
}

\author{
Sven Thatje
}

Published online: 10 December 2011

(C) Springer-Verlag 2011

In this editorial, I want to take the opportunity to summarise some of the key developments in Naturwissenschaften (NAWI) over the past 3 years and since the beginning of my tenure as editor in chief of the journal. Furthermore, I wish to raise awareness of some new changes to manuscript formats and promote the recently launched Concepts \& Synthesis article section in NAWI.

NAWI has undergone a series of structural changes since early 2009, which, in particular, addressed article types and formats (Thatje 2009). The loyal reader of the journal will have noticed that overall manuscripts have become more concise and that the editors have continuously encouraged authors to make use of Electronic Supplementary Material (ESM). ESM comprises information on, e.g. detailed methodological descriptions essential to the very specialist academic but not necessary for the more general reader to understand the main scientific message(s) proposed in an article. Overall, articles have therefore become shorter in length and more accessible; however, it has to be recognised that the various scientific disciplines represented by a multidisciplinary journal such as NAWI often demand flexibility in the text allowance of scholarly works. This means that although strict length limits as outlined in the instructions for authors are generally enforced, flexibility is given where appropriate.

Recently, the instructions for authors have been revised again, and new length restrictions are requested for Review articles as well as Short Communications. Review manuscript length should not exceed 50 manuscript pages including

\section{S. Thatje $(\bowtie)$}

National Oceanography Centre, Southampton, European Way, University of Southampton, Ocean and Earth Science,

Southampton SO14 3ZH, UK

e-mail: nawi@soton.ac.uk everything from the title page to the last figure, and may include up to seven figures and/or tables. Short Communications are now limited to a maximum of 2,500 words including everything from the title to the last reference, and may include a maximum of three figures and 30 references. This is in order to truly distinguish this article type from longer formats published.

What makes a Short Communication is often difficult to assess. In the current academic environment in which scientists are under pressure of publishing rapidly and frequently (Thatje 2010), journal editors are challenged by a flood of rather short incoming manuscripts for consideration as Short Communications. Often, such manuscripts reflect on limited data that do not make a full story for an Original Article and are therefore submitted as a shorter publication. In the current academic system in which not only the quality but also an aspect of quantity decides an academic's future, the scientist alone is probably not to blame. However, the value of such contributions can be of controversy and a problem in quality assessment, and therefore often requires discussion among editors in order to distinguish between what is valuable for a particular research area, and what is simply "not yet there".

The Comments \& Replies section introduced during 2009 can now be regarded as an established discussion forum in NAWI. Although the journal is not inundated with such discussions to date, those manuscripts that have been published provide a valuable contribution to assessing divergent views on a topic. I am keen on seeing this area develop further as I personally believe that overall, there is not enough open discussion of science in the literature these days.

I now welcome the introduction of a new paper format in NAWI, the Concepts \& Synthesis article. This article type in NAWI aims to promote the conceptual advance of ideas 
across the natural sciences. Concepts \& Synthesis articles present an evidence-supported opinion by established scientists on a research topic, ideally of cross-disciplinary nature. However, this paper format should not be confused with a traditional Review article and does not therefore aim at a balanced revision of a topic. Instead, Concepts \& Synthesis articles should stimulate thought on a controversial or widely ignored topic/problem, and at the same time develop and/ or direct new ideas for the research area(s) involved, beyond the current state of the art. Manuscripts should be concise and not exceed 30 manuscript pages in length including everything from the title page to references. Up to three figures or tables are allowed for this paper format, explaining relevant theories and/or discussing outstanding questions in support of the manuscript's core message. Legends to figures/tables can be longer than in a standard article format but should be no longer than 300 words. The reference list should not be review-like but set the background to the article, and Review articles should preferably be cited to reduce the number of references required. In consequence, no more than 50 references are allowed and authors are encouraged to simply refer to key literature to raise awareness of the complexity of the subject rather than excessively review the full body of published work on a topic. Few journals allow for theoretical works that stimulate, if not direct, new scientific thought beyond established knowledge. However, such theoretical work can be of groundbreaking impact and potentially direct the development of research areas.

The board of associate editors is a constantly developing environment and key appointments have been made especially in areas in which the journal has a high turnover of manuscripts. The board is striving to minimise handling times of manuscripts and I am glad to say that the assessment times from manuscript submission to first decision are extremely swift, thanks to joint effort taken by board members and NAWI main office. The journal has achieved a very competitive position in the pace of publishing scholarly work online. This is despite increasing the number of reviews per submitted manuscript to a minimum of three. It took me some time to understand why this strategy had worked out so well in comparison to other publishers and I have come to the conclusion that it is the frequent and direct communication with both authors and reviewers that speeds up handling time and assessment processes of manuscripts.

In 2013, NAWI will celebrate 100 years of existence. The journal has been a continuous promoter of the whole breadth of the natural sciences throughout its long history. Today, scientific publishing has probably reached unprecedented levels of competition and much of this is driven by the rapid development of electronic communication tools, such as online and open access publishing, and the rapid dissemination of knowledge through the worldwide web. The success of some more recently launched journals that have exclusively embarked on electronic publishing has to be recognised, and it is well possible that within a few years, the print format of journals may be a story of the past. NAWI still has to complete the transition into this new age in the years to come, and without jeopardising its grown academic identity at the same time.

\section{References}

Thatje S (2009) The science of nature. Naturwissenschaften 96:421422

Thatje S (2010) The multiple faces of journal peer review. Naturwissenschaften 97:237-239 